\title{
PENSAR Y TRATAR LA COOPERACIÓN DESDE EL DESARROLLO:
}

OBJECIONES

José Tonello*

\section{Un concepto de desarrollo}

Entendemos por desarrollo "el paso para toda la persona y para todas las personas de condiciones de vida menos humanas a condiciones de vida más humanas". Esta definición está tomada de la encíclica Populorum Progressio del Papa Paulo VI, publicada en 1967. En otro acápite de la misma encíclica se dice que "el desarrollo es el nuevo nombre de la paz". De esta encíclica toma su nombre y su inspiración el Fondo Ecuatoriano Populorum Progressio, a cuyas experiencias se refieren estas notas. En las definiciones antes enunciadas se utilizan los siguientes conceptos para definir el desarrollo:

- paso, o proceso, o movimiento constante;

- persona humana en cuanto unidad de cuerpo y espíritu y en cuanto a totalidad de pobladores de nuestra casa común, que es la tierra;

- condiciones de vida menos y más humanas: las menos humanas son,

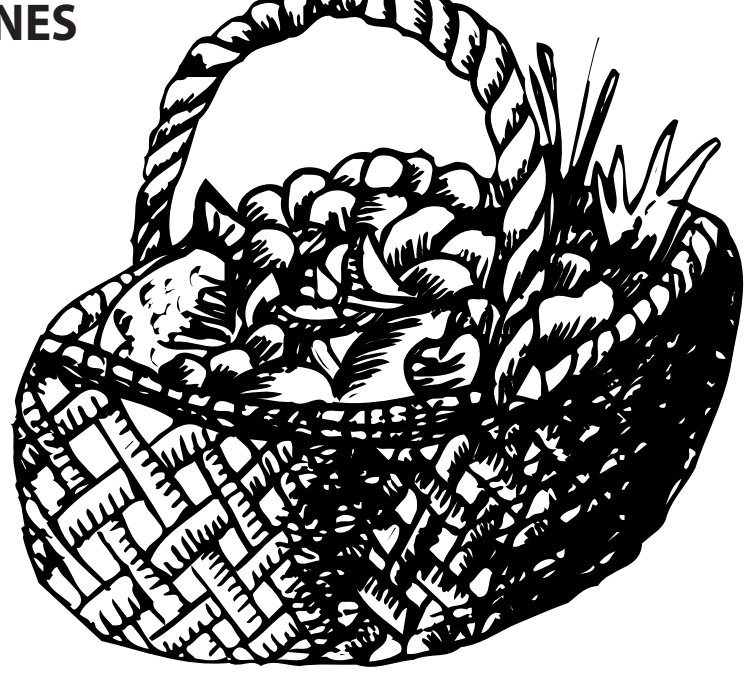

al mismo nivel de deshumanización, "las carencias del mínimo vital y las carencias morales de los que están mutilados por el egoísmo, las estructuras opresoras, que provienen del abuso del tener o del abuso del poder, de la explotación de los trabajadores y de la injusticia de las transacciones";

- la paz como punto de llegada final, junto con la felicidad, de toda búsqueda y construcción humana.

\section{El Grupo Social FEPP}

El FEPP es una fundación que nace en 1970, como agencia finan-

* Director Ejecutivo del FEPP (Fondo Ecuatoriano Populorum Progressio). 
ciera al servicio de y para los pobres del campo (por ello el nombre de "fondo"), en donde el crédito es su principal instrumento de trabajo, además de intentar ser una alternativa para los pobres frente a los usureros. A lo largo de 36 años de vida ha evolucionado en primer lugar hasta convertirse en una institución que promueve el desarrollo rural integral y luego, más recientemente, hacia el Grupo Social FEPP (GSFEPP), que incluye a 21 equipos, unos con personería jurídica propia y otros en perspectivas de obtenerla: una oficina central en Quito, diez oficinas regionales (Ibarra, Latacunga, Guaranda, Riobamba, Cuenca, Loja, Portoviejo, Esmeraldas, Lago Agrio, Coca), la Cooperativa de Ahorro y Crédito "CODESARROLLO" (matriz y 11 agencias), la comercializadora solidaria de productos campesinos "CAMARI" (matriz y 5 sucursales), la Escuela de Formación Empresarial "Monseñor Cándido Rada", FEPP Construcciones, AguaFEPP, ImpreFEPP, FEPP Protierras, Agroimportadora FEPP, YuraFEPP e InfoFEPP.

Mediante estos 21 equipos, que agrupan a un poco más de 350 personas (técnicos, promotores, administradores), el GSFEPP llega con su acción a 60.000 familias pobres, aproximadamente, en las 22 provin- cias del Ecuador. En 15 provincias actúa con mayor intensidad. Se trata de familias indígenas, afro-descendientes, mestizas; de pobladores rurales y urbano-populares; son jóvenes, hombres y mujeres, familiares de migrantes, etc. Son aproximadamente el $10 \%$ de la población rural pobre del Ecuador. Estas 60.000 familias forman cerca de 1.200 organizaciones de base (comunas, cooperativas, asociaciones), las mismas que, a su vez, han constituido más de 100 organizaciones de $2^{\circ}$ grado (uniones, federaciones, consorcios, redes).

\section{Propuesta de desarrollo del FEPP}

El FEPP ha construido una propuesta de desarrollo rural que se caracteriza por ser dinámica e integral; no es, por lo tanto, un modelo acabado. En esta propuesta de desarrollo lo central y realmente importante es la persona humana (hombre y mujer), considerada no en forma aislada, sino como parte de una familia y de una comunidad o de cualquier otra forma de organización.

A estas personas-familias-comunidades del sector rural y urbanopopular el FEPP quiere acompañarles en un proceso de desarrollo, entendido éste como el paso continuo y progresivo de condiciones de vida 
menos humanas (inhumanas) a condiciones de vida más humanas. Se trata de un desarrollo que tiene que ver con las personas y con la condición humana y no sólo con un conjunto de indicadores económicos de crecimiento.

El propósito no está en que las personas-familias-comunidades únicamente tengan más, sino que, a la par, sean más (sean mejores seres humanos). Por ello nos parece que el desarrollo que impulsamos está atravesado por aspectos éticos-humanistaspolíticos (solidaridad, honradez, responsabilidad en la relación hombrenaturaleza, equidad, participación cívica, desarrollo de la ciudadanía, empoderamiento y otros), y de otra, por el desarrollo de mercados locales, alimentados por la producción local, en los cuales los pobres tengan un rol activo, mercados que estén conectados con lo que ocurre en la realidad regional, nacional y mundial y, finalmente, por el acceso al bienestar (salud, educación, vivienda, agua, infraestructuras básicas, etc.)

El gran desafío consiste en que, en la práctica, estos tres grandes ejes, el ético-humanista-político, el económico-productivo y el infraestructu$\mathrm{ral}$, se interrelacionen y logren un sano equilibrio entre sí, pues según las épocas ha existido la tentación de dar prioridad a uno u otro. Actualmente, parecería que las condiciones del país $y$ del mundo enfatizan hacia una tendencia económica, circunstancia a la cual la cooperación internacional al desarrollo y entidades de desarrollo como el FEPP no están ajenas. Por eso es importante trabajar en forma permanente para el logro de este necesario equilibrio.

\section{El Ecuador de hoy}

Con casi $260.000 \mathrm{~km}^{2}$ de superficie y un poco más de 12000000 de habitantes residentes, el Ecuador es un país donde toda su población podría vivir bien gracias a la variedad y abundancia de los recursos naturales disponibles: tierra (agricultura y ganadería; primer exportador mundial del banano), mar (pesca), petróleo y minerales, bellezas paisajísticas y artísticas para el turismo, etc. En flora y fauna es uno de los países más biodiversos del mundo.

La población ecuatoriana está conformada en su mayoría por mestizos, el mestizaje se dio por la llegada de los conquistadores europeos. Los indígenas nativos y los negros descendientes de esclavos africanos forman minorías muy activas y dinámicas, las cuales plantean la constitución de un estado multiétnico y pluricultural, formado por todas las nacionalidades presentes en el Ecuador. Esta justa as- 
piración choca con una visión y una praxis de las relaciones humanas marcadas por el racismo.

El Ecuador es un país rico, pero lleno de pobres. El 30\% de la población vive por debajo de la línea de la indigencia (o pobreza extrema), es decir con menos de un dólar por día. Un 35\% vive por debajo de línea de la pobreza, esto es con más de un dólar y menos de dos dólares por día. Esto significa que dos personas sobre tres son pobres en el Ecuador. En las áreas rurales marginales en las cuales intervenimos con nuestro trabajo, estos porcentajes son todavía más dramáticos: el $80,6 \%$ de la población se encuentra por debajo de la línea de la pobreza y, dentro de este total, el $36,5 \%$ en pobreza extrema.

Ser pobre significa no tener la capacidad de resolver digna y sosteniblemente problemas de:

- alimentación

- salud

- educación

- vivienda

- empleo

Estas variables para medir son de tipo material, por ello la pobreza es más visible y fácilmente medible.

Ser pobres causa también otras clases de problemas, todavía más dolorosos:
- la discriminación

- la explotación

- la humillación

- la represión

- la falta de oportunidades

- la pérdida del autoestima

- el no pensar en el largo plazo

- las puertas que se cierran

- la administración de justicia que siempre castiga a los pobres

Frente a estas situaciones, la población ecuatoriana ha desarrollado diferentes estrategias de sobrevivencia o de cambio. La primera es la realización de actividades en el campo de la economía informal: esto significa hacer cualquier cosa, vender cualquier cosa, prestar cualquier servicio, sin horario, sin sueldo fijo, sin seguro de enfermedad y accidentes, sin jubilación para la vejez. Después de la economía informal, que permite algún nivel de acumulación, viene la emigración. En este momento la emigración es el fenómeno social y económico más importante del Ecuador. En los últimos 15 años han salido del país, con o sin papeles, algo más de 1500000 de personas. Las remesas de los emigrantes (casi 2.000 millones de dólares anuales) son la segunda fuente de ingresos para el país, después del petróleo.

Una tercera estrategia se nota en el aumento de la microcriminalidad, 
que involucra especialmente a jóvenes. Pero por suerte esto es marginal y el atraco del joven pobre que te roba la billetera no es comparable con la delincuencia de los banqueros (que se llevaron nuestra plata al exterior y todavía no la devuelven), de los narcotraficantes, de los contrabandistas de cuello blanco, de los grandes evasores de impuestos y de los políticos corruptos.

En 1970, el Ecuador tenía 6 millones de habitantes: de éstos el 65\% era población rural y el $35 \%$ población urbana. Hoy, con 12 millones de habitantes, esta proporción se ha invertido. De cada tres personas, dos viven en las ciudades y una en el campo. En el campo hay la mayor concentración de la pobreza extrema o indigencia (36,5 \% de la población), pero el flujo migratorio hacia las ciudades ha creado barrios muy pobres, auténticos cinturones de miseria, en los cuales las casas son precarias, no existe prestación de los servicios básicos, no hay empleo estable para los moradores. Las propuestas de desarrollo son pensadas e implementadas sea en áreas rurales empobrecidas o en barrios urbanos marginados.

La cooperación internacional tradicional está generalmente alejada de las estrategias que la población encuentra para resolver sus problemas: tiene su propia agenda y pro- gramas, que frecuentemente no coinciden con los esfuerzos y esperanzas populares.

\section{La máquina perversa}

Los mayores problemas que enfrenta el Ecuador son de orden cultural y estructural. En cada coyuntura estos problemas pueden tener una

\section{Los mayores problemas que enfrenta el Ecuador son de orden cultural y estructural.}

expresión diferente, pero su raíz profunda es la misma. Desde el tiempo de la Colonia en nuestra sociedad funciona perfectamente, a tiempo completo y en todos los ámbitos, una máquina perversa que concentra el poder y la riqueza, en vez de distribuirlos equitativamente.

Es una máquina querida y mantenida, con un mayor o menor nivel de conciencia y con ciertas concesiones a los reclamos de las mayorías, por el poder ejecutivo, el poder legislativo y por el poder judicial. Las Fuerzas Ar- 
madas y la Policía Nacional, excepto durante cortos momentos de atención y adhesión a las causas populares, se encargan de mantener un orden interno, que es expresión del pecado social que mancha la vida nacional. Ni las universidades, ni los medios de comunicación social contribuyen eficazmente a poner en discusión este modelo concentrador, mientras la banca tradicional es su expresión más visible e instrumento más eficaz. La misma desigualdad en la distribución de la riqueza, que se encuentra en el Ecuador, existe también entre países ricos y países pobres del mundo. La máquina perversa funciona en el mundo entero. Para que exista desarrollo verdadero, la máquina de la concentración debe ser reemplazada por la cultura de la equidad, a nivel nacional y a nivel mundial.

\section{La cooperación internacional al desarrollo en el contexto geopolítico mundial}

La cooperación al desarrollo es una realidad que ha crecido después de la segunda guerra mundial. Antes no había grandes expresiones de interés por el desarrollo de los pueblos pobres. En efecto, el colonialismo ha sido un instrumento de saqueo y dominación, antes que una transferen- cia de conocimientos y una instancia de equidad. Sin embargo de ello, las Iglesias y especialmente la Iglesia Católica han tenido, a través de los misioneros y misioneras, notables intervenciones en el campo de la educación, la salud, la difusión de algunas tecnologías y el rescate de la dignidad de la persona humana.

Hoy constatamos que las diferencias en todos los campos, entre el Norte y el Sur del Mundo, están aumentando. Son diferencias económicas, sociales, tecnológicas, políticas. En el Norte se concentra mucha riqueza, poder, tecnología y bienestar. El desarrollo genera desarrollo. La riqueza se multiplica. El consumo de materias primas y de energía crece en forma preocupante, afectando los destinos de toda la humanidad, incluso de aquella parte que no quiere o no puede ser presa del consumismo.

Pero tal vez no aumenta la felicidad. Y ¿qué es el desarrollo, sino una constante e intensa búsqueda y construcción de felicidad? Quien ya tiene todo lo material posible, tal vez será más feliz cuando tenga un poco menos. Quien tiene demasiado poco y no logra satisfacer las exigencias suyas y de sus familiares en asuntos de alimentación, vestido, vivienda, salud, educación, empleo y participación en la sociedad, tal vez llegue a ser más feliz cuando pueda tener un 
poco más. Porque en este caso el tener algo más es indispensable para llegar a saber, poder y ser más.

Una más equitativa distribución de las riquezas es una exigencia irrenunciable del desarrollo humano. Frente al fracaso mundial de los intentos políticos por redistribuir la riqueza (y por ende el poder), los países más ricos del mundo han puesto en funcionamiento la cooperación internacional. Pero la riqueza sigue concentrándose porque hay fuerzas políticas, militares, económicas y comerciales que lo propician. Las principales leyes del comercio mundial son un tributo a quien ya es muy fuerte y un desafío a los débiles. El Norte del mundo tiene el poder de fijar los precios de lo que vende al Sur y de lo que le compra. Este doble poder evidentemente sirve los intereses de quienes lo ejercen. La cooperación internacional hasta ahora no ha sido capaz de cambiar esta situación, salvo realizar esfuerzos admirables, pero absolutamente insuficientes.

\section{Más allá de las modas}

Cada tres o cuatro años, los expertos en temas de desarrollo (personas o instituciones) sacan una fórmula para resolver los problemas de los pobres, que son la absoluta mayoría de la población mundial. Antes de la Segunda Guerra Mundial no había programas de desarrollo, siendo el colonialismo el más importante tipo de relación entre el Norte y el Sur del mundo, o sea entre los países en su mayoría ricos y los países pobres. Terminada la guerra, se ejecuta el "Plan Marshal", financiado por los Estados Unidos, para la reconstrucción de Europa. Del enfoque asistencial de los años 50 se pasa en los años 60 a la aplicación de la Reforma Agraria y a la propuesta de la Revolución Verde. Vienen después los temas de la educación y la organización popular, de la participación ciudadana, de la capacitación, de las equidades (todas las equidades), del respeto a las identidades de cada persona y de cada pueblo, de las finanzas populares, del acceso a mercados justos, de la ecología y el buen uso de los recursos naturales, de las obras de infraestructura, del papel regulador del estado, etc. Cada uno de estos temas fue tratado como si fuera el tema, la única estrategia, la mejor propuesta, la fórmula mágica. Las solicitudes de financiamiento para programas y proyectos frecuentemente no se aprobaban, si no tenían como argumento central o como eje trasversal el tema de moda. 
En realidad hemos aprendido que todos los temas antes enunciados son importantes, pero que no se crea desarrollo enfocando uno u otro y prescindiendo de una visión que los englobe a todos. El punto de partida puede ser cualquiera de ellos $u$ otro también, pero, en la medida que una comunidad se conoce a sí misma y establece una relación de confianza con quienes (personas e instituciones) puedan ayudarla a caminar hacia el desarrollo, es indispensable enfrentar también las otras áreas problemáticas en un orden no preestablecido, respetando los intereses, necesidades y voluntad de la gente. En este sentido el "desarrollo" no es una fórmula o una receta que garantiza éxitos espectaculares, sino el resultado de muchos esfuerzos, coordinados entre sí, durante largos años, con la ayuda de abundantes recursos humanos, tecnológicos y financieros.

Si bien el "desarrollo" hay que medirlo utilizando indicadores que descubran y valoricen "el paso de condiciones de vida menos humanas a condiciones más humanas", en realidad los cambios más profundos en la lucha contra la pobreza son los que suceden al interior de las personas y de las comunidades. La pobreza está en la cabeza de la gente: en la cabeza de los ricos que concentran en su beneficio los frutos del sudor ajeno, y en la cabe- za de los pobres, que frecuentemente tienen miedo a pensar algo alternativo, a organizarse, a educarse, a poner en discusión sus prácticas productivas, a construir mercados nuevos, a sentirse independientes y capaces.

Si la cabeza de los ricos es difícil de cambiar (lo decía Jesús cuando hablaba del camello y la aguja), nosotros tenemos experiencias positivas sobre como los pobres, especialmente jóvenes, superan los miedos y entran en el espacio de la libertad, de los derechos, de las responsabilidades y de economías más dinámicas.

\section{Las ONG's del Sur entre la dependencia y la crisis}

A partir de los años 60, en Ecuador como en otros países de América Latina y del mundo, tomó vigencia la constitución de ONG's con objetivos relacionados a la promoción, el desarrollo, la producción, la ecología, la cultura, la investigación, etc. Hacia el final de los años '80, esta tendencia se intensificó porque las ONG's, hechas o por hacer, fueron el refugio de muchos servidores públicos que perdieron sus empleos por los procesos de modernización que todos los países comenzaron a implementar con mayor o menor intensidad. Algunas quedaron engañadas por una oferta inconstante de recursos, otras tratan 
de adaptarse al impacto de ciertos temas de moda para la opinión pública y para los planificadores del desarrollo en todo el mundo: se enfatizó primero la educación popular, el autoabasto de alimentos, después la ecología, el enfoque de género, etc.

Hace 15 años, la oferta de recursos de parte de la cooperación internacional, aunque reducida frente a la globalidad de las necesidades, era todavía abundante frente a la capacidad operativa y la voluntad de transformación de las ONG's. Por esta razón muchas de ellas cometieron errores, principalmente porque pensaron que todo iba a ser fácil, que bastaba pedir para conseguir, que no había que medirse con los resultados conseguidos, sino con las intenciones proclamadas.

Como se recibían muchos recursos de fuera con relativa facilidad, no se desarrolló la capacidad y la voluntad de autofinanciarse, creció la dependencia, se perdió de vista la austeridad. Era como estar dentro de un círculo vicioso que llevaría a la mediocridad y por ende a la disminución de la credibilidad (sea frente a las agencias financieras, sea frente a la población destinataria de la acción). No faltaron instituciones que implementaron procedimientos administrativos y decisionales alejados de la honradez, la transparencia y la austeridad. Todas garantizaron una remuneración fija a sus empleados, independientemente de los resultados alcanzados.

Mientras tanto, el mundo de los pobres se hacía siempre más grande y exigente en su participación al reparto de los recursos que los países ricos destinan al desarrollo; en consecuencia los fondos comenzaron a disminuir. Capacitadas por las mismas ONG's muchas organizaciones populares, de base, de segundo y de tercer grado, comenzaron a solicitar directamente fondos en el exterior, ganándose simpatía y apoyo concreto.

Los países europeos establecieron prioridades que los alejaban de América Latina: nos demostraron y nos demuestran que les interesa más canalizar los fondos para el desarrollo hacia África, para disminuir la presión migratoria dirigida al viejo continente y hacia Europa del Este, ampliando en esta última su presencia comercial. Aparentemente, lo más grave de la crisis consiste en una mayor dificultad para conseguir financiamiento. Este aspecto es más bien la consecuencia de una serie de inconsistencias ideológicas, metodológicas, operativas y administrativas que han caracterizado en mayor o menor medida el trabajo de las ONG's. En realidad parecería ser que el discurso, las propuestas y el traba- 
José Tonello

\section{En realidad parecería ser que el discurso, las propuestas y el trabajo de las ONG's no han dado todos los frutos que se esperaba.}

jo de las ONG's no han dado todos los frutos que se esperaba.

La crisis actual puede marcar un importante momento de crecimiento en la medida en que sepamos juntar armónicamente objetivos de tipo social y objetivos de tipo económicoproductivo; en la medida en que realicemos nuestro trabajo disminuyendo los costos y aumentando los beneficios; en la medida en que seamos más eficientes que el aparato estatal y más justos que el aparato empresarial privado; en la medida en que nuestra presencia en las comunidades contribuya a prevenir la disgregación social y el triunfo de la ley del más fuerte. La crisis no es un callejón sin salida. Es el momento del juicio, de la toma de decisiones para ir delante o para retroceder, para vivir plenamente o para sobrevivir, para ser excelentes o ser mediocres.

\section{Las prácticas de financiamiento de las ONG's}

Hasta ahora la mayor parte de los recursos de que han dispuesto las ONG's se han originado en las solicitudes que éstas presentan a entidades nacionales y principalmente del exterior. A veces bastaba una carta para fondos pequeños, otras veces había que hacer un proyecto. Si el monto solicitado era muy alto se redactaban programas acompañados por diagnósticos, estudios de factibilidad, relación costo-beneficio, planificaciones estratégicas, etc. En fin, pedíamos y recibíamos. Si una institución u organización no sabía preparar el texto de un proyecto, bastaba contratar a una persona para que lo redactara.

Se dio también la posibilidad de solicitar y recibir fondos anuales fijos, ya sea para gastos de administración o para proyectos. Cada ONG del Sur llegó a tener sus contrapartes financieras, más o menos fieles, en el Norte y viceversa. Las ONG's del Sur y del Norte buscaron evitar riesgos, pero en muchos casos no pudieron evitar el riego de la mediocridad derivado de la aplicación de fórmulas preestablecidas y de cupos asignados.

Poco a poco, las financieras se hicieron más exigentes. Pretendieron una definición más exacta de objetivos, actividades e indicadores; estable- 
cieron prioridades por áreas geográficas, por sujeto social y por línea de acción; implementaron sistemas más objetivos de evaluación -ex ante y ex post- de los impactos de nuestra acción. Y también los destinatarios se hicieron más críticos, más capaces de leer nuestras realidades institucionales, aun las que hubiéramos querido tener escondidas. En síntesis, hubo un tiempo en que se conseguían muchos recursos con extrema facilidad, bastaba pedir y recibíamos. Por eso se constituyeron tantas ONG's. Hoy estamos constatando que lo fácil no lleva lejos.

\section{Los problemas ligados a lo fácil}

Como ha sido fácil conseguir dinero, las ONG's, en mayor o menor medida, hemos incurrido en problemas, limitaciones y fallas ligadas a bajos perfiles de eficiencia, eficacia y calidad, como los siguientes:

- no hemos desarrollado suficientemente la capacidad de autofinanciarnos;

- hemos generado un sistema administrativo con altos costos fijos;

- hemos implementado proyectos discutibles o insignificantes en término de resultados;

- hemos tomado decisiones equivocadas;
- hemos perdido la austeridad y la sobriedad;

- hemos renunciado a la creatividad.

En otro orden de cosas, no se excluye que puedan haberse dado actuaciones de las ONG's ligadas a la falta de transparencia, al desvío de fondos, a la duplicación de financiamientos, al aprovechamiento simple y llano. Y para que no se piense que los problemas han estado todos de un solo lado, cabe señalar que a veces llegamos a conocer conductas discutibles de las mismas financieras: sus costos, sus imposiciones, sus cambios de normas de conducta y prioridades hasta hacerse más sensibles a las modas que nosotros, su desigual valoración del trabajo humano (un profesional del Norte que nos presta una consultoría cuesta escandalosamente más que un profesional del Sur -o cualquiera de nosotros- que hace lo mismo con idénticos o mejores resultados), su apego a las formalidades, aun cuando estas sacrifican la vida, etc.

\section{La crisis de la Cooperación Internacional}

Esta visión crítica de la debilidad estructural de muchas ONG's de los países en desarrollo, no debe hacernos perder de vista la problemática 
de las entidades de cooperación internacional, sean éstas multilaterales, estatales o privadas. Parece que ciertos sectores de la cooperación internacional, especialmente la multilateral y la estatal, han desviado tanto de su misión que su fin principal es ahora mantenerse a sí mismas. No es fácil conseguir números y porcentajes que indiquen cuánto cuesta el funcionamiento de los grandes organismos internacionales y cuánto efectivamente éstos destinan al objetivo por el cual fueron creados, o sea los niños, las mujeres, los refugiados, los campesinos, etc. Es posible entonces que estos sujetos sociales se utilicen como instrumento para conseguir recursos que les llegarán sólo en medida muy reducida.

El GSFEPP, en sus "Orientaciones para el trabajo" del año 2003, hace esta observación:

"El constante aumento de las diferencias en las condiciones de vida de las poblaciones del Sur pobre y del Norte rico crea peligros para la paz mundial. Si es cierto, como afirma la Populorum Progressio, que 'el desarrollo es el nuevo nombre de la paz', entonces la paz se construye y se garantiza impulsando el desarrollo y la equidad".

La concentración del poder, de la tecnología y de la riqueza en el Nor- te del planeta trae consigo un imparable flujo de migración desde el Sur hacia el Norte, que no se reduce con leyes represivas y la imposición de visas, sino con una redistribución de la riqueza, el bienestar y las posibilidades de empleo bien remunerado en todo el mundo.

El cambio de las reglas que norman la economía mundial es uno de los requisitos para que cada persona pueda aprovechar los frutos de su propio sudor. Para el desarrollo de los pueblos este aspecto es más importante y determinante que la cooperación internacional, multilateral y bilateral. Mientras existan estructuras de explotación, la ayuda externa es sólo un paliativo, que ni de lejos logra devolver a los pobres lo que les quita una práctica sistemática de explotación y de concentración de la riqueza, ejercida por las empresas multinacionales y por los países que tienen el poder político, militar, económico y el poder del conocimiento científico y de la tecnología.

El FEPP denuncia con fuerza que un sector de la cooperación internacional tiende a transformarse en objetivo en vez de ser instrumento del cambio. Cada vez más, con los recursos de la cooperación internacional se financian viajes, estancia en hoteles, encuentros, congresos, páginas 
web, CD-ROM, video-conferencias, consultorías, asesorías, estudios, investigaciones, sistematizaciones, $\mathrm{pu}-$ blicaciones, filmaciones, sueldos muy elevados, jugosos viáticos, muchas veces sin escatimar gastos. Los hoteles deben ser de 4 ó 5 estrellas, los vuelos ya se quiere hacerlos en "business class", los consultores si no son caros no valen. Y por el hecho de que han sido caras, sus recomendaciones se toman como infalibles y de obligada aplicación, aunque a veces carezcan de viabilidad, de conocimiento de la realidad y hasta de sentido común.

No pretendemos decir que algunas de estas cosas no sean importantes, pero los pobres quedan lejos de todo esto. Dar un dólar a un pobre es considerado paternalista e insostenible; dar 500 dólares diarios o más a un consultor, que a veces desorienta en vez de orientar, es perfectamente normal y sostenible. La cooperación se vuelve entonces un negocio y no un deber de solidaridad y de equidad. Es necesario volver a la ética según la cual los recursos de la cooperación internacional lleguen de forma directa -con el menor número de intermediarios que sea posible- $y$ abundante a los pobres y no alimenten el mundo de los que dicen dedicarse a resolver los problemas de los pobres. Estos defectos se encuentran más en la cooperación pública, multilateral y bilateral, que en la cooperación privada.

Afortunadamente hay un gran número de ONG's dedicadas a la cooperación y a la solidaridad internacional que merecen toda nuestra admiración y aprecio, porque actúan con inteligencia, creatividad, austeridad y sobriedad, ganándose así la confianza de los pobres. Las personas que trabajan en estas ONG's dan testimonio de su solidaridad, compromiso y opción a favor de los pobres. Cada vez con mayor insistencia los sectores populares organizados nos piden cuentas de lo que hemos hecho con los recursos que recibimos por ellos y para ellos. Es nuestro deber dárselas.

Será importante convocar a mesas de diálogo y concertación a todos los niveles (local, regional, nacional, continental) con el fin de reafirmar los contenidos, los valores, los objetivos y el estilo de la cooperación internacional, para el desarrollo de los pueblos, partiendo de la admisión de que los pobres tienen el derecho de ser informados, de juzgarnos y de tomar un mayor protagonismo en la gestión de los programas y proyectos que los afectan. 
Debemos cuidar que algunos de los vicios y desviaciones antes denunciados no encuentren ningún espacio en el FEPP. Mons. Rada, nuestro fundador, nos ha enseñado y demostrado que los recursos de los pobres, o destinados a los pobres, son sagrados".

Además de lo anterior, se nota que a veces la cooperación internacional llega a los países en desarrollo y no toma en cuenta la exigencia y urgencia de fortalecer institucionalmente a sus contrapartes locales o, lo que es más grave todavía, compite directamente con ellas, dificulta su crecimiento y sustrae recursos, porque abre sus propias oficinas en los países en desarrollo. A veces esto se hace con actitudes de superioridad y de desconfianza.

\section{Proyectos y procesos}

Los problemas de la pobreza, en países ricos de recursos naturales como el Ecuador, se derivan principalmente de lo que pasa en la cabeza de las personas (de los ricos y de los pobres) y en las modalidades de funcionamiento de la sociedad. Son entonces problemas de orden cultural y estructural. Los cambios en la cultura $\mathrm{y}$ en las estructuras requieren de tiempos largos. No se trata entonces sólo de implementar proyectos de pocos años de duración, sino de impulsar procesos que a veces duran décadas. Los proyectos, si son coherentes entre sí, son sólo un momento y una parte de los procesos. La coherencia al interior de los procesos es garantizada por la dirigencia de los sectores populares y por la institucionalidad y formalidad de las entidades que los impulsan.

\section{Los tiempos del desarrollo}

Los tiempos de un proceso, que tiene componentes culturales y estructurales, no los puede determinar la institución que aporta financiamiento, ni la que hace de intermediaria local; éstos son determinados por la población que vive el proceso, y no siempre coinciden con la planificación técnica que se ha hecho. Si hablamos de procesos (y no de proyectos) hablamos de tiempos bastante largos. Pensamos que 10-15 años es un tiempo adecuado para que los proyectos (que duran pocos años) incidan en la cultura de la gente y en las estructuras de funcionamiento de la sociedad. En esto a veces no tenemos coincidencia de puntos de vista con nuestras contrapartes financieras y técnicas de la cooperación internacional, que prefieren ligar sus intervenciones a los proyectos y a las consultorías, o sea a los tiempos cortos. 
La mayor causa de la pobreza está ligada a la manera de ser de las personas y al funcionamiento de las estructuras sociales: cambiar a las personas y a las estructuras requiere de tiempos largos. Si estos cambios han sido profundos y sinceros, los procesos de desarrollo serán sostenibles y duraderos. Si han sido superficiales y oportunistas, los cambios tendrán la misma duración de los proyectos que los han inducido.

\section{Cambios más profundos}

En tiempos de globalización, con un mundo que se hace cada vez más pequeño, con tiempos y costos de comunicación y movilización más reducidos, cuando hablamos de un país como el Ecuador, hablamos de lo local, sea en relación con el resto del continente americano, sea más genéricamente en el contexto de las relaciones Norte-Sur. Los problemas que nos angustian (pobreza, emigración, deuda, corrupción, racismo, mediocridad, etc.) nos hacen sentir unidos frente a un mundo desarrollado que, en cierta medida, es también causante de nuestras calamidades.

Para que nuestras esperanzas y reivindicaciones se transformen en motores del desarrollo local-nacional, es indispensable que el Ecuador defina políticas y estrategias de de- sarrollo, que sean propias del Estado, que vayan más allá de la duración de un gobierno o, peor todavía, del tiempo que dura un ministro en un ministerio. Deberían ser políticas de consenso, capaces de unificar y orientar los esfuerzos de todo el país.

Lamentablemente no las hay, porque los intereses de pocos todavía prevalecen sobre los intereses de las mayorías, sobre el bien común. Quienes trabajamos en la construcción del desarrollo integral exigimos que el Estado, a través del Gobierno de turno, asuma y ejerza sus responsabilidades en la construcción de obras de infraestructura (carreteras, acueductos, canales, electrificación, etc.) y en la prestación de servicios de salud y educación.

Junto con esto sentimos también que, en la máquina de la economía

\section{La cooperación internacional oficial está lejos de alcanzar los niveles que los propios países, en un gesto demagógico, se pusieron como metas.}


global, somos parte de un engranaje que, si no cambia, siempre nos mantendrá pobres. El tercer mundo llegará a ser cuarto o quinto mundo, si no cambian algunas leyes y estilos de la economía y de la política: necesitamos y pedimos relaciones comerciales más equitativas (no tanto tratados de "libre" comercio, sino tratados de "justo" comercio), revisión de la carga injusta de la deuda externa, libertad para la movilización de las personas, como la hay para los capitales y las mercaderías, control de los elementos contaminantes que provocan el cambio climático, que causa más daños a quienes son más vulnerables como los pobres, control del tráfico de armas con la misma fuerza que se aplica al tráfico de estupefacientes, liberalización de las patentes que permitirían la curación de millones de personas con costos bajos, etc. Si no cambian algunas cosas alrededor del mundo, seguiremos siendo pobres, como país, como pueblo, a pesar de que algunos procesos de desarrollo sean exitosos y la cooperación internacional siga dándonos recursos. Si no se planifica y ejecuta una redistribución de la riqueza entre el Norte y el Sur del mundo, los desequilibrios sociales se harán siempre más grandes.
Nuestro ingreso per cápita (2.000 dólares anuales en el Ecuador, con desproporciones enormes entre unos pocos que pueden acaparar 200.000 y muchísimas personas que no llegan a 200) no podrá llegar a 5.000 (no pedimos mucho), si no hay una reducción o una redistribución de los ingresos de quienes hoy tienen más de 20.000. Esto se consigue en el Norte consumiendo menos energía y materias primas, pagando mejor los productos del Sur y realimentando aquella tradición de solidaridad y cooperación internacional que en estos últimos años parece debilitarse. Pero es probable que esta reflexión esté fuera del tema del desarrollo y sea más bien un planteamiento político.

Las personas y las familias de cada comunidad son el principio y el fin de todo proceso de desarrollo sostenible y equitativo. El desarrollo sostenible y equitativo se puede definir como un proceso endógeno de cambios y transformaciones, que conducen al surgimiento de comunidades autosuficientes, capaces de mejorar la calidad de su vida y de encontrar respuestas a sus necesidades elementales, descubriendo y movilizando sus propios recursos y ventajas, sin degradar los recursos naturales y sin depender de constantes ayu- 
Pensar y tratar la cooperación desde el desarrollo

das externas. Son comunidades que crean riqueza humana, cultural $y$ económica.

En el Grupo Social FEPP pensamos, hablamos y trabajamos con el fin último de que todos y todas sean felices y vivan en paz. Ser felices y vivir en paz, cada uno en su tierra, bien puede ser el objetivo final del desa- rrollo y de la cooperación internacional que lo sostiene.

José Tonello

Director Ejecutivo GSFEPP

Quito, 2 de junio de 2006

JT/gq 